\title{
Derivation of volatile fatty acids concentration-independent optimum trace elements configuration and elucidation of optimization kinetics of biomethanization processes
}

\author{
Ezebuiro, N. C. \\ Hamburg University of Technology, Eissendorfer Straße 42, D-21073 Hamburg, Germany. \\ National Biotechnology Development Agency, Umar Musa Yar'Adua Expressway, Abuja, Nigeria.
}

\begin{abstract}
Trace elements (TES) requirements for improved volatile fatty acids (VFA) degradation during biomethanization depend on VFA concentration of a reactor and the temperature of the process. While temperature remains relatively constant, VFA concentrations change in the course of biomethanization and this implies that for efficient VFA degradation, different trace elements configurations (TEC) should be supplemented. While this is the most efficient approach, it is impractical and constitutes a challenge for the effective use of TEs in the optimization of biomethanization processes. To alleviate this challenge, we modelled the biomethanization efficiency of various VFA concentration-dependent (VCD) TEs configuration as scenarios and derived a TEs configuration that produced optimum biomethanization across a wider range of VFA concentrations. The study was carried out at $37^{\circ} \mathrm{C}$ using different concentrations of fixed VFA composition and TEs configurations as scenarios. Response surface model and desirability function were used to determine and compare the biomethanization efficiency of the scenarios, and to derive a VFA concentration-independent (VCI) TEs configuration. Michaelis-Menten kinetics for two parameters was used to ascertain that the mechanism by which TEs supplementation enhanced mesophilic biomethanization was through an increase in maximum reaction rate (MRR). However, the enhancement was accompanied by an insignificant decline in inverse affinity (IA).
\end{abstract}

Keywords: Trace elements, maximum reaction rate, inverse affinity, biomethanization, degradation rate

Corresponding Author's email: n.c.ezebuiro@nabda.gov.ng

\section{Introduction}

Trace elements (TEs), including nickel (Ni), cobalt (Co), selenium (Se), tungsten (W) and molybdenum (Mo), influence anaerobic digestion (AD) both positively and adversely (Ariunbaatar et al., 2016; Facchin et al., 2013; Yazdanpanah et al., 2018). TEs requirements during biomethanization is influenced by organic loading rate (OLR) and the concentrations of volatile fatty acids (VFA) in the different biomethanization phases (Ezebuiro et al., 2018; Myszograj et al., 2018). The relationship between VFA concentration and TEs configuration (composition and concentration) implies that for enhanced VFA metabolism, different TEs configurations are required at the starting and ending of biomethanization (low VFA concentrations) and at the acidification stage (peak of VFA concentration). In part, different TEs configuration are needed with changes in VFA concentration due to changes in identity of the individual species of VFA and the inhibition arising from the accumulation of certain VFA species such as propionic- and acetic acid (Amani et al., 2010; Li et al., 2012; Wainaina et al., 2019; Lukitawesa et al., 2020). It is also possible that due to differences in the enzymology of the phases of biomethanization, the different dominant metallo-enzymes (MEs) of the phases may require specific TEs for 
activation and activity enhancement (IngramSmith et al., 2005; Ragsdale and Pierce, 2008). While there is justification for the differences in TEs requirements for different levels of VFA, in practical operation of a biogas digester, a single dose of TEs mixture is often administered (Braga et al., 2018; Mancini et al., 2018). Single dose application of TEs formulations remains the most feasible and practical approach. Hence, a scientific approach to the formulation of a single TEs configuration for medium level VFA concentration during $A D$ was developed (Ezebuiro et al., 2018). The authors acknowledged that the single TEs supplementation dose has biomethanization weaknesses at certain VFA levels and phases. In addition, the understanding of the bioenhancement mechanism of TEs supplementation, especially with regards to VFA degradation is very weak.

It has been documented that the different biomethanization phases and processes require MEs whose activities are enhanced by the presence of certain TEs (Demirel and Scherer, 2011; Glass and Orphan, 2012; Ortner et al., 2015). The activities of MEs in the biomethanization processes they mediate can be evaluated by measuring two parameters in the Michaelis-Menten function: maximum reaction rate $(M R R)$ or maximum velocity $\left(V_{\text {max }}\right)$, and inverse affinity $(I A)$ or the half saturation constant of the substrate, $K_{M}$ (Illanes, 2008). MRR reflects the maximum rate of substrate utilization or product formation per time. It is the maximum rate of the enzyme for a single enzyme assay, or the net process rate for a multi-enzyme process such as $A D$. A relative increase in MRR could imply an increase in the concentration of the relevant enzyme(s) through synthesis of new enzymes or an optimization of the activities of existing enzyme(s). Thus, for any substrate, changes in the MRR due to changes in process conditions could be compared for the different operating conditions.

IA is the substrate concentration at which half the MRR is attainable (Bisswanger, 2001). IA is influenced by both substrate binding, affinity, and substrate conversion efficiency (Illanes, 2008). For a given process, a small IA value indicates that the MRR will be reached more quickly compared to a larger $I A$. Hence, relatively small $I A$ is an indication of better affinity for the substrate being degraded.
Michaelis-Menten function is shown in Equation 1 , and its derivations are shown in Equation 2 and 3. Equations 1,2 and 3 depict the relationship between $M R R, I A$ and substrate concentration $[S]$ when the enzyme concentration $[E]_{0}$ is much less than the substrate concentration [S], a condition that is satisfied during biomethanization in AD.

$$
\begin{aligned}
& v=V_{M A X} \frac{[S]}{K_{M}+[S]} \\
& v=k_{c a t}[E]_{o} \frac{[S]}{K_{M}+[S]}
\end{aligned}
$$

Or simply put:

$$
\begin{aligned}
& v=\frac{a *[S]}{b+[S]} \\
& v=k_{\text {cat }}[E]_{o} \frac{[S]}{K_{M}} \\
& V_{\text {max }}=k_{\text {cat }}[E]_{o}
\end{aligned}
$$

In Equation 1-5, $v$ is rate of reaction at any time; $[S]$ is the substrate concentration; $V_{\max }$ or $a$ is the maximum reaction rate (MRR); $K_{M}$ or $b$ is the inverse affinity (IA); $k_{c a t}$ is the maximum number of substrate molecules converted to product per enzyme molecule per second; and $[E]_{o}$ is the (initial) enzyme concentration.

Under very small substrate (VFA) concentration, that is, when $[S]$ is much less than $K_{M}$ or $b$ (comparable to the starting and ending of biomethanization), the rate of the reaction $v$, is limited by [S]. Similarly, under abundant substrate concentration (comparable to acidification and acetogenesis stages), Equation 4 applies to the enzyme catalysed reaction. Under the abundant substrate concentration, the rate of reaction $v$ is determined by the enzyme properties including the (initial) enzyme concentration $[E]_{o}$ and the catalytic potential of the enzyme, $K_{\text {cat }} . K_{\text {cat }}$ is the maximum number of substrate molecules converted to product per enzyme molecule per second. Details of the Michaelis-Menten equation and the behaviour of $v$ under various substrate conditions have been well documented (Bisswanger, 2001; Illanes, 2008).

The current study combines experimental and advanced statistical analyses to:

i. Derive a TEs configuration that enhances biomethanization 
processes across a wider VFA concentration;

ii. Elucidate the prevailing kinetic mechanism of mesophilic AD enhancement by TEs supplementation.

\section{Materials and Method}

Trace Elements and Basic Nutrient Solution: Separate solutions were prepared for each of the TEs that include $\mathrm{Ni}, \mathrm{Co}, \mathrm{Se}$ and Mo. A nutrient solution that did not contain any of the TEs was also prepared following the procedure described earlier (Ezebuiro, 2014). The substrate used for this study was a mixture of VFA comprising sodium salts of acetic-, propionic- and butyric acids and was prepared as earlier described (Ezebuiro et al., 2018). The experimental inoculum was obtained from a continuously operated mesophilic digester in Hamburg, Germany, which was exclusively fed with maize silagebased feedstock (MSF). The inoculum was placed in a water bath that was maintained at $37^{\circ} \mathrm{C}$ until the start of the experiment. Prior to the study, the inoculum was analysed for dry matter (DM) following DIN EN 12880), organic dry matter (oDM), following DIN EN 12879 and TEs (Ni, Co, Se and Mo) following DIN EN 13346:2001-04.
Design of Experiment and the Experimental Test Set Up: The design of experiment (DoE) was factorial with five factors $(k)$, including concentrations of $\mathrm{Ni}, \mathrm{Co}$, Se and Mo and VFA mixture, and was studied in three levels $(n)$ designated as low, medium and high. The low levels of $\mathrm{Ni}, \mathrm{Co}$, Se and Mo were the respective average concentrations in the inoculum used for the study. The choice of the $\mathrm{Ni}, \mathrm{Co}$, Se and Mo concentrations used in this study were oriented on published report including Zhang and Banks (2010; 2012); Zhang et al. (2012); and Lo et al. (2012); and the VFA concentrations and levels were chosen based on earlier publications including Ahring et al. (1995). The DoE resulted in 243 experimental runs $(e)$, following Equation 6.24 implementable runs were selected from the 243 experimental runs following procedures documented in JMP 10 (SAS Institute Inc. 2012a).

$e=n^{k}$ .Eq. 6

The experimental test system was designed based on the VDI 4630 (Verein Deutscher Ingenieure, 2006); and is shown in Figure 1. The experiment was carried out in batch mode at $37^{\circ} \mathrm{C}$ inside 1 Litre glass reactors.

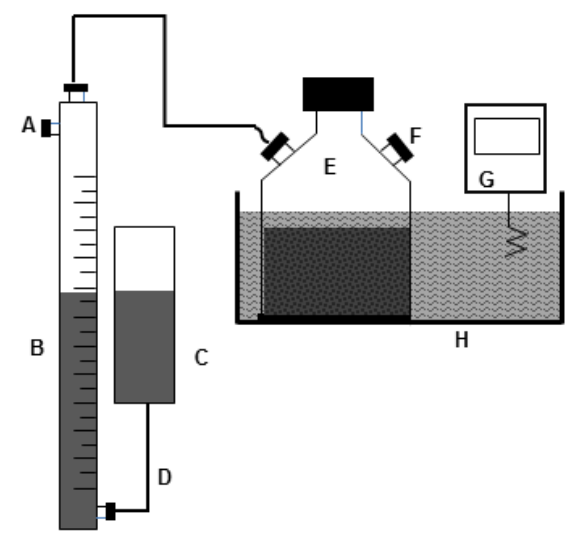

Figure 1: Basic scheme of the anaerobic digestion test system used to determine the influence of TEs on volatile fatty acids degradation rate and methane production. Note: The test system comprised the following parts: A-gas sampling port; B-eudiometer; C-barrier solution in reservoir bottle; D-tube connection; $\mathrm{E}-1$ litre glass reactor; F-liquid sampling port; G-thermostat; $\mathrm{H}$-water bath.

The test system comprised 24 units of $1 \mathrm{~L}$ glass reactors (R) consisting of 3 Controls and 21 treatment reactors. The experimental runs were divided into 3 groups based on the level of VFA as shown in Appendix -Table 1. All reactors were connected to the eudiometers, a system of columns, which allowed the determination of biogas volume by displacement of the liquid inside the columns, as shown in Figure 1. The reactor-eudiometer set-up was flushed with dinitrogen gas as recommended in VDI 4630 (Verein Deutscher 
Ingenieure, 2006). Each experimental run was performed in duplicate.

Sample Collection: For content homogeneity and release of gas bubbles, the reactors were manually shaken for about 10 seconds twice daily. Liquid and gas samples were collected once in 3 or 4 days through the sampling ports using $20 \mathrm{~mL}$ and $50 \mathrm{~mL}$ syringes respectively. Liquid and gas samples were collected, stored and analysed as reported in Ezebuiro et al. (2018).

Responses: VFA degradation rate (VDR) was measured as change in VFA concentration per time. VFA retention time (VRT) was measured as time (days) needed to convert at least $75 \%$ of the total VFA concentration that was present at the start of the experiment; that is, when the condition in Equation 7 was satisfied. Methane production was measured as the product of methane content (\%) and biogas volume measured over same period for any reactor.

(cTVFA, $0-c T V F A, t \leq$

$$
(0.25 * c T V F A, 0) \leftrightarrow V R T=t \ldots \ldots . . \text { Eq. } 7
$$

In Eq. 7: $C T V F A s, 0$, is the concentration of the total VFA (mmol/L) at the beginning of the experiment $(\mathrm{t}=0) ; \quad C T V F A s, t$, is the concentration of the total VFA (mmol/L) measured at any time ( $t$ ) within the experimental period for a given reactor; and $V R T$ is the VFA retention time in days.

For direct comparison of the treatment reactors with the corresponding Control, relative response values were derived using Equation 8. Relative value ( $Y_{\text {relative }}$ ) of VDR, VRT or $\mathrm{CH}_{4}$ production $>1$ is beneficial, $=1$ is equal to the Control, and $<1$ is non-beneficial.

Yrelative $=\frac{Y \text { treatment }}{\text { Ycontrol }}$ Eq. 8

In Eq. 8: $Y_{\text {treatment }}$ is the response value of a treatment reactor in a particular VFA level; and $Y_{\text {control }}$ is the response value of the Control reactor in the same VFA level.

TEs Supplementation Scenarios: A scenario is an alternative combination of factors (Sascha Meinert, 2014; Varum and Melo, 2010). A TEs supplementation scenario is a mixture of TEs comprising $\mathrm{Ni}, \mathrm{Co}$, Se and $\mathrm{Mo}$ in different configurations (Ezebuiro and Ina, 2017). TEs configurations and VFA concentrations were used to distinguish between the scenarios. The following scenarios, summarized in Table 1, were considered:

Table 1: Features of the different TEs supplementation scenarios

\begin{tabular}{l|l}
\hline SCENARIO & DEFINITION \\
\hline $\begin{array}{l}\text { CONTROL TES } \\
\text { SUPPLEMENTATION } \\
\text { SCENARIO }\end{array}$ & $\begin{array}{l}\text { This is the TEs configuration in the inoculum used for the investigation. It } \\
\text { is expected to serve as a basis of comparison with the other scenarios. } \\
\text { The TEs configuration in this scenario is expected to provide the lower } \\
\text { limits of the responses of interest. }\end{array}$ \\
$\begin{array}{l}\text { COMPROMISE TES } \\
\text { SUPPLEMENTATION } \\
\text { SCENARIO }\end{array}$ & $\begin{array}{l}\text { This is a mixture of TEs containing the medium level concentration of Ni, } \\
\text { Co, Se and Mo as used in the investigation and shown in Appendix-Table } \\
1 . \text { This TEs configuration is a Compromise between the high and the low } \\
\text { concentrations of the TEs; hence, its influences on the responses are } \\
\text { expected to be a subset of the VFA-independent TEs configuration. }\end{array}$ \\
$\begin{array}{l}\text { VFA-120 TES } \\
\text { SUPPLEMENTATION } \\
\text { SCENARIO }\end{array}$ & $\begin{array}{l}\text { This TEs configuration is the optimum concentration of Ni, Co, Se and Mo } \\
\text { for biomethanization of 120 mmol/L VFA. 120 mmol/L VFA is considered } \\
\text { to be within the appropriate range of VFA concentration for } \\
\text { biomethanization (Ahring et al., 1995). }\end{array}$ \\
VFA-DEPENDENT & $\begin{array}{l}\text { This comprises a number of TEs configurations, each of which is } \\
\text { optimum for a specific VFA concentration. This is the VFA concentration- } \\
\text { Teps }\end{array}$ \\
SUPPLEMENTATIOnt (VCD) scenario. The TEs configurations in this scenario are \\
SCENARIO & $\begin{array}{l}\text { expected to provide the upper limits (best values) of the responses for } \\
\text { the specific VFA concentrations. }\end{array}$ \\
\hline
\end{tabular}


Statistical Analyses: Two statistical functions were used to determine the influences of the scenarios on the responses. These methods include response surface model and desirability function.

Response Surface Model: Response surface model (RSM) as documented in JMP 10 was used to determine the relationships between the TEs configuration and VFA concentrations of the scenarios and the responses. Details of the RSM algorithm are documented in JMP 10 (SAS Institute Inc., 2012b, 2012c). Equation 9 shows the specific RSM for the experimental factors (Ni, Co, Se, Mo and VFA).

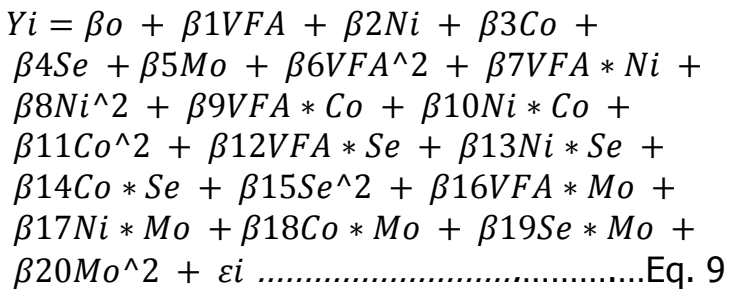

In Eq. 9, $Y i$ is the response that is being modelled (VDR, VRT or $\mathrm{CH}_{4}$ production); $\beta O$ is the intercept calculated with the RSM algorithm in JMP $10 ; \beta i \ldots \beta k$ are the estimated coefficient of regression (CR) for the factors' main effects and interactions; $X 1 i \ldots X k i$ are the factors ( $\mathrm{Ni}, \mathrm{Co}, \mathrm{Se}, \mathrm{Mo}$ and VFA) and all the interactions between two factors; and $\varepsilon i$ is the prediction error for the responses.

Desirability Function: Desirability function (D) as documented in JMP 10 was used to determine and compare the biomethanization efficiencies of the scenarios. $D$ ranges between 0 (weak) and 1 (strong). Details of RSM and D function for single and multiple response(s) have been reported (SAS Institute Inc., 2012b; Suich and Derringer, 1980). D for multiple responses is the geometric mean of the individual desirability as shown in Equation 10.

$$
D_{1-k}=\left[D^{e}{ }_{1} \times D_{2}^{f} \ldots \times D_{k}^{z}\right]^{1 / k} \ldots \ldots \ldots \ldots . . . E q .10
$$

In Equation 10, $e, f$ and $z$ are the relative importance of the responses. In this study, each of the responses was ranked equally; so, each of $e, f$ and $z$ is equal to $1 ; D_{1} \ldots D_{k}$ are the desirabilities of the individual responses ( 1 to $k$ ) being evaluated at any given time.
By comparing the desirability of the different scenarios for specific range of VFA concentration and for the multiple responses (VDR, VRT and $\mathrm{CH}_{4}$ production), the VFA concentration-independent (VCI) TEs configuration that is optimum for a wide range of VFA was determined. The VCI is a specific TEs configuration whose influence on the multiple-responses at wider range of VFA concentrations is expected to be comparable to the influence of the VFA-dependent scenario.

Mechanism of Methanization Enhancement due to TEs Supplementation: The Michaelis-Menten function for two kinetic parameters (Equation 1-5) were used to determine the mechanism by which TEs supplementation improved mesophilic biomethanization in the scenarios. For each scenario, the average VDRs of specific VFA concentrations $(50-, 100-, 150-$, $200-$, and $250 \mathrm{mmol} / \mathrm{L}$ ) were predicted using the RSM (Equation 9). Michaelis-Menten function (Equation 1) was fitted to the predicted VDRs ( $p$ VDRs) of the scenarios to estimate the MRR and IA. The MRR and IA for each scenario were compared with the mean MRR and IA of the four scenarios for significance of differences using the Dunnett's Analysis of Mean (Dunnett, 1955).

\section{Results and Discussion}

The experimental inoculum had the following properties: $\mathrm{pH} 7.7 \pm 0.1 ; \mathrm{DM}$ (\% fresh matter) $9.34 \pm 1.4$; and oDM (\% DM) $74.5 \pm$ 0.60 . The experimental periods of the study were 41 days in the high VFA level, 33 days in the medium VFA level, and 29 days in the low VFA level. Details of the statistical analyses leading to the derivation of the VFA-120 (Optimum) TEs configuration has been published (Ezebuiro et al., 2018). Response data for the scenarios including TEs configuration (mg/L), VFA levels ( $\mathrm{mmol} / \mathrm{L})$, relative VDR, relative VRT, relative $\mathrm{CH}_{4}$ production are shown in Appendix -Table 2.

\section{Comparison of VFA Degradation Rates across Scenarios}

Figure 2 shows a comparison of the mean values of the relative VFA degradation rates (rVDRs) across the four scenarios. The average rVDR of the four scenarios is 1.58, and the lower decision limit (LDL) and upper decision limit (UDL) are 1.38 and 1.77 respectively. 
Whereas the average rVDR for the Control scenario is 1.11 , the Compromise scenario has an average relative value of 1.63 . VFA- 120 scenario has an average rVDR of 1.80 ; while the VFA-dependent scenario has an average rVDR of 1.75. Having optimum TES configuration, the VFA-120 and the VFAdependent scenarios have significantly higher average rVDR compared to the Compromise scenario with sub-optimal TEs configuration. This is expected given earlier publications that interactions between TEs and VFA concentrations are more important in influencing biomethanization processes and the optimality of TEs configurations (Ezebuiro, 2018; Ezebuiro et al., 2018; Ezebuiro and Koerner, 2017).

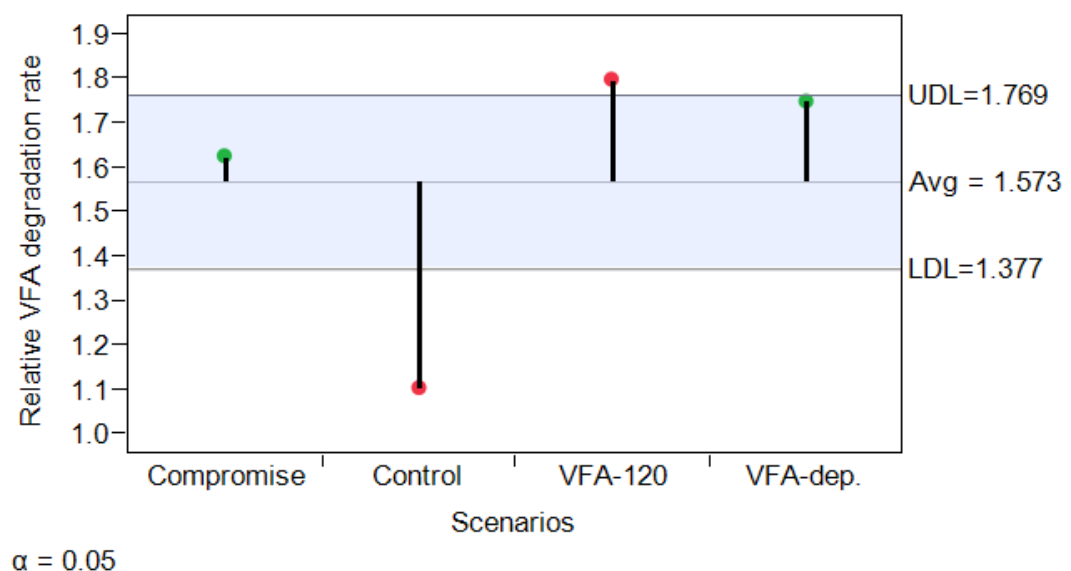

Figure 2: Comparison of the VFA degradation rates of the four scenarios (Compromise, Control, VFA120 or optimum TEs configuration for VFA concentration of $120 \mathrm{mmol} / \mathrm{L}$; and VFA-dep. or optimum TEs configurations for VFA concentrations between 10 - and $250 \mathrm{mmol} / \mathrm{L}$ )

Comparing VFA Retention Time across the Scenarios

Figure 3 shows a comparison of the relative VFA retention time (rVRT) across the four scenarios.
The average rVRT of the scenarios is 1.31 , and the LDL and UDL are 1.20 and 1.42 respectively.

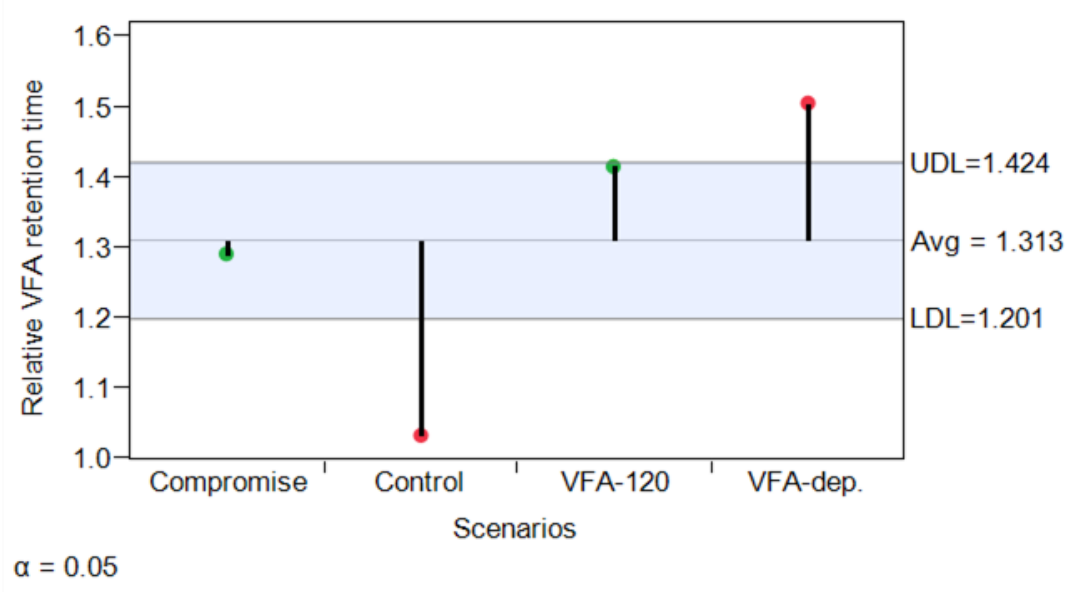

Figure 3: Comparison of the VFA retention time of the four scenarios (Compromise, Control, VFA-120 or optimum TEs configuration for VFA concentration of $120 \mathrm{mmol} / \mathrm{L}$; and VFA-dep. or optimum TEs configurations for VFA concentrations between 10 - and $250 \mathrm{mmol} / \mathrm{L}$ )

The rVRT for the Control is 1.04. The Compromise scenario has rVRT of 1.29. For VFA-120 scenario, the rVRT is 1.42; while for the VFA-dependent scenario, it is 1.51 . The two scenarios with significant effect on VRT as shown in Figure 3 are the Control- and the VFA-dependent scenarios. Whereas the 
VFA-dependent scenario exceeded the UDL of the group effect and stands out with a $51 \%$ reduction in VRT, the Control scenario had far less effects on VRT than the average effect produced by the other scenarios. The performance of VFA-dependent scenario compared to the VFA-120 scenario with regards to VRT confirms earlier publications that TEs enhance VFA degradation rate (Myszograj et al., 2018; Wainaina et al., 2019) and that VFA-dependent TEs configurations for digester biomethanization produces best VDRs, notwithstanding its lack of practicality.

\section{Comparing $\mathrm{CH}_{4}$ Production across the TES} Supplementation Scenarios

Figure 4 shows a comparison of the relative $\mathrm{CH}_{4}$ production across the scenarios. The average relative $\mathrm{CH}_{4}$ production of the scenarios is 1.43, and the LDL and UDL are 1.20 and 1.66 respectively. The average relative $\mathrm{CH}_{4}$ production for the Control scenario is 1.04. The Compromise scenario has a relative $\mathrm{CH}_{4}$ production of 1.48. VFA-120 scenario has an average relative $\mathrm{CH}_{4}$ production of 1.63; while for VFA-dependent it is 1.58. Differences in relative $\mathrm{CH}_{4}$ production exist between the Compromise, VFA-120 and VFA-dependent scenarios; however, these are insignificant $(a=0.05)$. The Control scenario has a significantly lower average relative $\mathrm{CH}_{4}$ production $(a=0.05)$ compared to the other scenarios that received supplementation of TEs. This observation is consistent with other studies (Braga et al., 2018; Da Silva et al., 2021). Theoretically, the volume of $\mathrm{CH}_{4}$ derivable from the scenarios' VFA concentration is fixed; however, the rate at which the theoretical volume will be reached will vary depending on the biocatalytic potential of the scenarios. Hence, the lack of difference in $\mathrm{CH}_{4}$ production between the TES scenarios is understandable given that the relative values of the $\mathrm{CH}_{4}$ were derived from cumulative $\mathrm{CH}_{4}$ data, which were obtained at the end of the experiment.

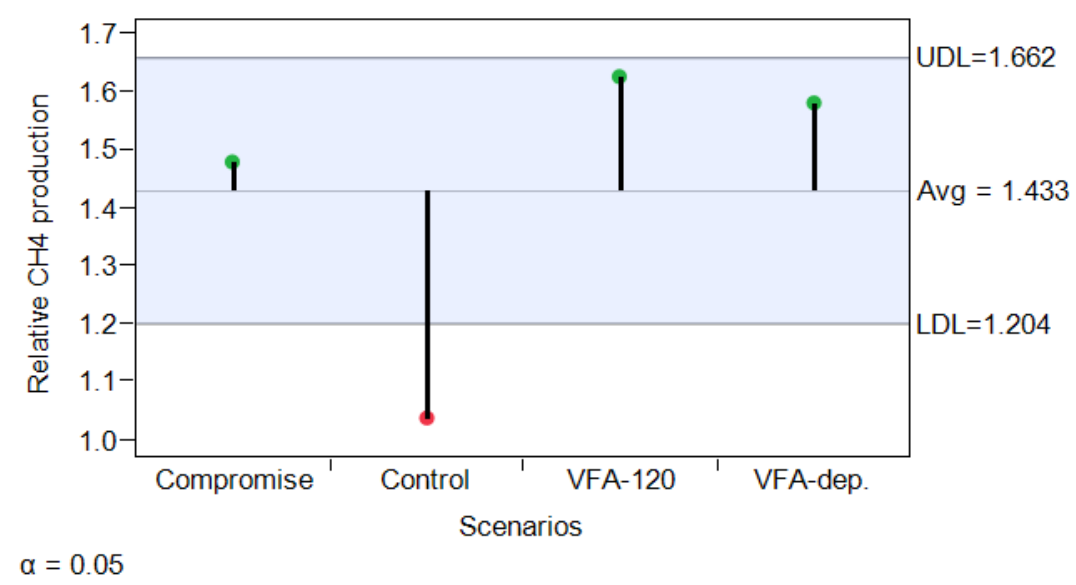

Figure 4: Comparison of the $\mathrm{CH}_{4}$ production of the four scenarios (Compromise, Control, VFA-120 or optimum TEs configuration for VFA concentration of $120 \mathrm{mmol} / \mathrm{L}$; and VFA-dep. or optimum TEs configurations for VFA concentrations between 10 - and $250 \mathrm{mmol} / \mathrm{L}$ )

Comparing Desirability across the Scenarios: Figure 5 shows the desirability, which is an indication of the biomethanization process efficiency when VDR, VRT and $\mathrm{CH}_{4}$ production were simultaneously optimized across the scenarios. The Control scenario has an average desirability of 0.31 , which is significantly lower than the desirability of 0.61 achieved by the
Compromise scenario. The two scenarios with optimum TEs configuration have average desirability values of 0.69 (VFA-120) and 0.72 (VFA-dependent). The immediate implication of this is that TEs supplementation enhances biomethanization efficiency by over $100 \%$ relative to the Control. 


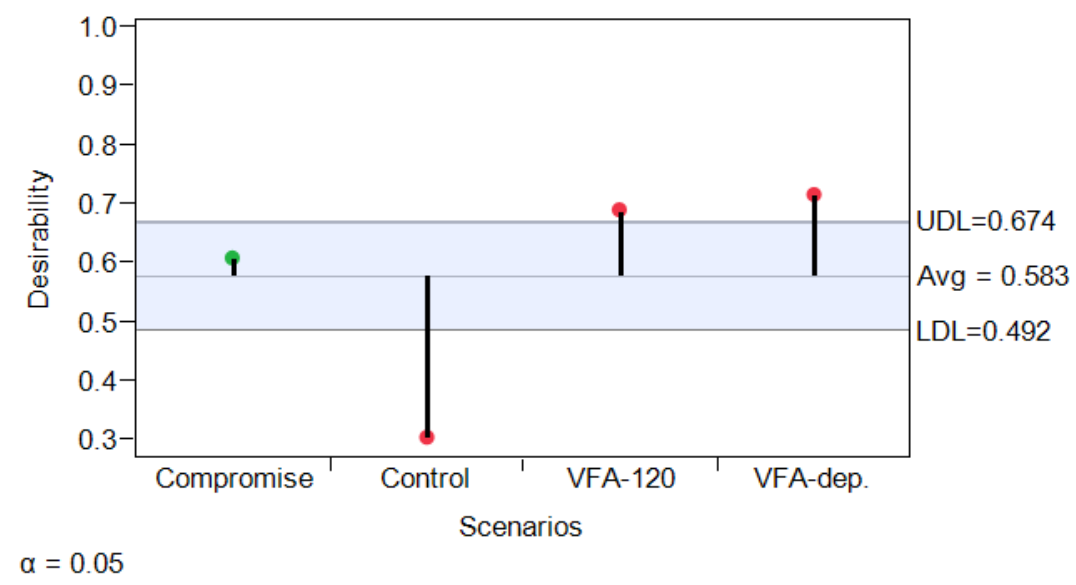

Figure 5: Comparison of the desirability of the four scenarios (Compromise, Control, VFA-120 or optimum TEs configuration for VFA concentration of $120 \mathrm{mmol} / \mathrm{L}$; and VFA-dep. or optimum TEs configurations for VFA concentrations between 10 - and $250 \mathrm{mmol} / \mathrm{L}$ )

Overall, the low desirability of the Control scenario compared to the TEs supplemented scenarios is consistent with reported low process efficiency during the $A D$ of food waste under conditions of nutrient deficiency (Zhang and Banks, 2010; Myszograj et al., 2019). Similarly, the observed enhancements in biomethanization in the TEs supplemented scenarios agree with published reports on TEs-based improvements in the stability of the biomethanization of different substrates including synthetic model substrate (Pobeheim et al., 2010), wheat silage (Gustavsson et al., 2011) and industrial food waste (Feng et al., 2010).

\section{Derivation of the VCI Scenario}

The differences in desirability between the optimum scenarios (VFA-120 and VFAdependent) and the Compromise scenario highlight the importance of optimality in TEs configuration. The similarity in desirability between VFA-120 and VFA-dependent suggests that VFA-120 could meet the TEs requirements for a wide range of VFA concentration during substrate biomethanization. Although statistically insignificant, the lower desirability in the VFA120 scenario suggests an inherent operational weakness in biomethanization efficiency at certain VFA concentrations.

The VFA concentrations at which biomethanization efficiencies were impaired in the VFA-120 TEs supplementation scenario is in the 10- and $250 \mathrm{mmol} / \mathrm{L}$ VFA as seen in Appendix -Table 2. Whereas the average desirability values of the VFA-120 scenarios at VFA concentrations of 10 -and $50 \mathrm{mmol} / \mathrm{L}$ is
0.81 , the average desirability value for the VFA-dependent scenario at the same VFA concentrations is 0.86 . Similarly, at 250 $\mathrm{mmol} / \mathrm{L}$ VFA, the VFA-dependent scenario has a higher desirability value (0.59) compared to the VFA-120 scenario (0.54). Within the optimum digester operating VFA concentration (200 $\mathrm{mmol} / \mathrm{L}<$ VFA > $50 \mathrm{mmol} / \mathrm{L})$, the average desirability values of VFA-120 and VFA-dependent scenarios are similar ( 0.66 and 0.67 respectively). This implies that the weakness in biomethanization efficiency is in the extreme VFA concentrations (10 - 50 $\mathrm{mmol} / \mathrm{L} \mathrm{VFA}$; and 200 - $250 \mathrm{mmol} / \mathrm{L}$ VFA). These VFA ranges correspond to the VFA concentrations in the beginning and ending of biomethanization (10 - $50 \mathrm{mmol} / \mathrm{L}$ VFA) and during digester acidification ( $>200 \mathrm{mmol} / \mathrm{L}$ VFA). Therefore, Figure $2-5$ indicate that VFA-120 scenario is comparable to VFAdependent scenario in promoting rapid VDR, reducing VRT and improving $\mathrm{CH}_{4}$ production during stable biomethanization. Based on the effects similarities between VFA-dependent and the VFA-120 scenarios, the TEs configuration of the VFA- 120 scenario is considered a VFA concentration-independent (VCI) TEs configuration.

Michaelis-Menten Kinetic Parameters of the Scenarios

The estimates of the Michaelis-Menten kinetic parameters are presented in Table 2 . The estimate of the kinetic parameter from each scenario is compared with the overall mean of the four scenarios to determine whether the differences in the parameters are significant or not (a 0.05). 
Table 2: Parameter estimates, lower- and upper 95\% confidence intervals and relative estimates of the Michaelis-Menten kinetic parameters for the four scenarios

\begin{tabular}{rrrrrr}
\hline Scenario & Parameter & Estimate & $\begin{array}{r}\text { Lower } \\
\mathbf{9 5 \%} \text { CI }\end{array}$ & $\begin{array}{r}\text { Upper } \\
\mathbf{9 5 \%} \text { CI }\end{array}$ & Rel. Estimate \\
\hline Compromise & MRR & 14.1 & 11.6 & 14.6 & 1.58 \\
\hline Control & IA & 76.9 & 54.3 & 100.9 & 1.02 \\
\hline MFA-120 & IA & 75.1 & 41.7 & 113.5 & 1.00 \\
\hline VFA-dep. & MRR & 15.5 & 11.5 & 14.8 & 1.00 \\
\hline IA & 86.4 & 52.9 & 102.3 & 1.74 \\
\hline & MRR & 14.4 & 11.7 & 14.5 & 1.15 \\
\hline IA & 72.4 & 56.3 & 98.9 & 0.96
\end{tabular}

(CI: confidence interval; MRR: maximum reaction rate (mmol/L/d); IA: inverse affinity ( $\mathrm{mmol} / \mathrm{L})$; Rel. Estimate: relative parameter estimate)

\section{Maximum Reaction Rate}

Figure 6 a shows a comparison of the estimates of the process MRR for the four scenarios. The average MRR for the group of scenarios is $13.12 \mathrm{mmol} / \mathrm{L} / \mathrm{d}$. Table 2 shows that the three scenarios with TEs supplementation (Compromise, VFA-120 and VFA-dependent) have MRR estimates that are higher than the group average. It also shows that the differences could range from $74 \%$ in an optimum scenario (rel. value of 1.74: VFA-120) to $58 \%$ in a sub-optimal scenario (Compromise). Figure 6a confirms that the differences in the improvements of the MRR of the three TEs supplemented scenarios are significant compared to the MRR of the Control scenario. This, while consistent with earlier findings of TEs effects on biomethanization (Ariunbaatar et al., 2016; He, et al., 2018; Meegoda, et al., 2018; Myszograj et al., 2019), also clearly corroborates reports of the ability of TEs supplementation to significantly induce increase in rate-related phenomenon during AD (Zhang et al., 2016). In addition, Table 2 shows that the VFA- 120 scenario has an MRR improvement that is significantly superior to the Compromise and VFA-dependent scenarios. MRR enhancement due to TEs supplementation holds huge potential for mesophilic $A D$, especially for digesters experiencing instability due to the accumulation of such recalcitrant VFA species as propionic acid.

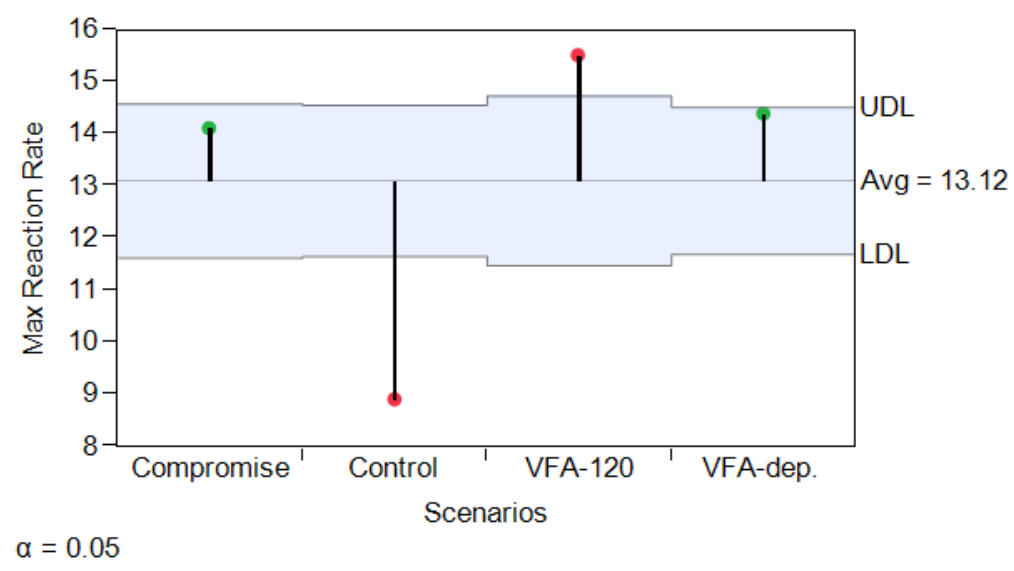

Figure 6a: Comparison of the estimates of the Michael-Menten MRR for the four scenarios (Compromise, Control, VFA-120 or optimum TEs configuration for VFA concentration of $120 \mathrm{mmol} / \mathrm{L}$; and VFA-dep. or optimum TEs configurations for VFA concentrations between 10 - and $250 \mathrm{mmol} / \mathrm{L}$ ) 


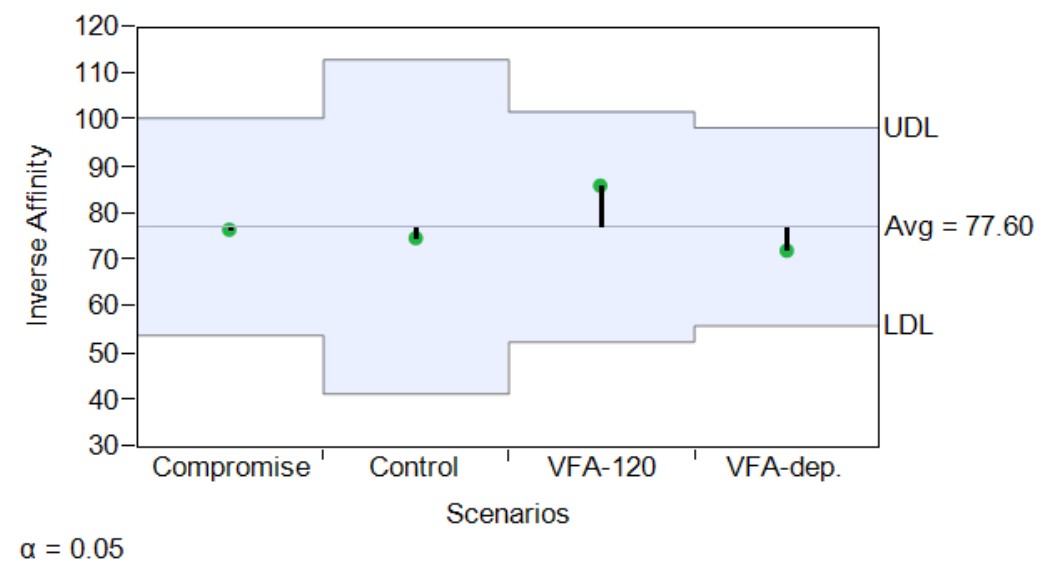

Figure 6b: Comparison of the estimates of the Michael-Menten IA for the four scenarios (Compromise, Control, VFA-120 or optimum TEs configuration for VFA concentration of $120 \mathrm{mmol} / \mathrm{L}$; and VFA-dep. or optimum TEs configurations for VFA concentrations between 10 - and $250 \mathrm{mmol} / \mathrm{L}$ )

\section{Inverse Affinity}

Figure $6 \mathrm{~b}$ compares the IA of the four scenarios. The average IA for the group is 77.6 $\mathrm{mmol} / \mathrm{L}$ VFA. Table 2 shows that differences exist in the IA of the different scenarios. However, Figure $6 \mathrm{~b}$ indicates that the differences in IA of the four scenarios are not significant irrespective of the significantly diverse MRR they support. This is confirmed in Figure $6 \mathrm{~b}$ where the IA of the Control (75.1 $\mathrm{mmol} / \mathrm{L}$ ) with the poorest MRR (Figure $6 \mathrm{a}$ ) is not significantly lower than the IA of the VFA120 scenario $(86.4 \mathrm{mmol} / \mathrm{L} / \mathrm{d})$ that has the most impressive MRR. Although in practical digester operation, small and insignificant loss in substrate affinity could be problematic due to the impact that the accumulation of a VFA specie such as propionate could have on biomethanization stability (Bardi and Aminirad, 2020).

\section{Mechanism for TES Enhancement of Methanization Processes}

Figure 6a confirms that TEs supplementation is capable of significantly enhancing the maximum substrate utilization and product formation potentials of the enzymology associated with the different phases of biomethanization. This observation is corroborated by the report of Ingram-Smith et al. (Ingram-Smith et al., 2005) who observed that $\mathrm{Ni}$ and other divalent metals activate, modify and enhance the kinases associated with the metabolism of VFA. Although the significant mechanism of TEs enhancement of biomethanization processes is by improvement of the MRR, Figure $6 \mathrm{~b}$ shows minor decline in substrate affinity in the VFA-120 scenario compared to the other scenarios; but the differences are not statistically significant. According to Ingram-Smith et al. (2005), because the binding pockets at the active sites of the kinases of acetate and propionate are similar, the binding of one could lead to loss in affinity or temporarily retard the binding of the other. This is understandable because although propionate was the dominant specie of acid in the VFA mixture, acetate and butyrate were also present in substantial proportion (Appendix-Table 1). Amani et al. (2010) had reported that in a mixture of VFA, acetate and butyrate will inhibit propionate degradation during mesophilic biomethanization. Notwithstanding, this report shows that TEs supplementation may not improve substrate affinity significantly, but it improves the conversion rate of bound substrates. This might be the reason for the improved VDR, VRT and MRR in spite of lack of improvement in the IA.

\section{Conclusion}

The VFA-120 and VFA-dependent TEs supplementation scenarios are comparable in terms of multi-criterial optimization potentials (average desirability value of 0.69 and 0.72 respectively). Therefore, the TEs configuration of the VFA-120 could be used as a VFAconcentration-independent TEs mixture for the improvement of biomethanization processes across a wide VFA concentration. The study also shows that TEs supplementation using a 
mixture of $\mathrm{Ni}, \mathrm{Co}$, Se and $\mathrm{Mo}$ in mesophilic condition enhances the MRR of a mixture of VFA with propionic acid as the dominant VFA specie. However, TEs supplementation did not improve the substrate IA significantly.

\section{Acknowledgement}

The author is thankful to Hamburg University of Technology (TUHH) for funding the laboratory analyses during this study. The laboratories of the Institute for Wastewater Management and Water Protection, and the Institute for Environmental Technology and Energy Economics at the TUHH are strongly appreciated for providing special analytical support. The author is also thankful to Herrling Group, Hamburg for providing the inoculum used for the study. PD Dr.-Ing. habil. Ina Koerner and Prof. An-Ping Zeng are highly appreciated for supervising this study; and the National Biotechnology Development Agency (NABDA) is appreciated for granting the author a study leave to conduct this study.

\section{Funding}

The scholarship enabling the author to conduct this study at TUHH, Germany, was granted by the German Academic Exchange Programme (DAAD): grant number $\mathrm{A} / 10 / 90006$.

\section{References}

Ahring, B. K., Sandberg, M. and Angelidaki, I. (1995). Volatile fatty acids as indicators of process imbalance in anaerobic digestors. Appl. Microbiol. Biotechnol. 43, 559-565. https://doi.org/10.1007/s002530050451

Amani, T., Nosrati, M., Mousavi, S. M. and Kermanshahi, R. K. (2010). Study of syntrophic anaerobic digestion of volatile fatty acids using enriched cultures at mesophilic conditions. Int. J. Environ. Sci. Technol. 8(1), 83-96. Doi: 10.1007/BF03326198.

Angelidaki, I. and Batstone, D. J. (2011). Anaerobic Digestion: Processes. Solid waste Technology and Management. Vol. 2, T.H. 583 - 600 Christ. (Ed.), Wiley, UK 2, 583-600.

Ariunbaatar, J., Esposito, G., Yeh, D. and Lens, P. (2016). Enhanced anaerobic digestion of food waste by supplementing trace elements: Role of selenium (vi) and iron (ii). Front. Environ. Sci. 4(8), 1-11. https://doi.org/DOI 10.3389/fenvs.2016.00008
Bardi, M. and Aminirad, H. (2020). Synergistic effects of co-trace elements on anaerobic codigestion of food waste and sewage sludge at high organic load. Environ. Sci. Pollut. Res. 27, 18129-18144. doi: DOI 10.1007/s11356-02008252-y.

Bisswanger, H. (2001). Practical Enzymology. Wiley-VCH, Germany, Weinheim.

Buchholz, K., Kasche, V. and Bornscheuer, U. T. (2005). Biocatalyst and the enzyme technology. Wiley VCH, Weinheim.

Braga, A. F. M., Pereira, M. B. O. C., Zaiat, M., Gustavo H., Da Silva, R. and Fermoso, F. G. (2018). Screening of trace metal supplementation for black water anaerobic digestion. Environ. Technol. (39)14, 17761785, DOI: $10.1080 / 09593330.2017 .1340343$

Da Silva, J. A., Braga, A. F. M., Fermoso, F. G., Zaiat. M. and Gustavo H. R. S. (2021). Evaluation of the influence of trace metals on methane production from domestic sewage, using the Plackett-Burman experimental design. J. Environ. Manage. 294, 113002. DOI: 10.1016/j.jenvman.2021.113002

Demirel, B. and Scherer, P. (2011). Trace element requirements of agricultural biogas digesters during biological conversion of renewable biomass to methane. Biomass Bioenergy 35, 992-998. https://doi.org/10.1016/j.biombioe.2010.12.02 2

Douglas, C. M. (2001). Introduction to statistical quality Control, 4th ed. John Wiley and Sons Inc.

Dunnett, C. (1955). A multiple comparison procedure for comparing several treatments with a Control. J. Am. Stat. Assoc. 50, 10961121.

https://doi.org/10.1080/01621459.1955.10501 294

Ezebuiro, N. C. (2018). Dynamics and the interaction effects of trace elements and volatile fatty acids concentrations on biomethanization processes during thermophilic anaerobic digestion. Nig. $J$. Biotech. 35, 53-61. https://doi.org/DOI: https://dx.doi.org/10.4314/njb.v35i1.7

Ezebuiro, N. C. (2014). Optimization of Anaerobic Digestion: Influence of Trace 
Elements on Methanization Processes. Hamb. Ber. Siedlungswasserwirtsch. 87, 1-212. ISBN 978-3942768-122

Ezebuiro, N. C. and Koerner, I. (2017). Characterisation of anaerobic digestion substrates regarding trace elements and determination of the influence of trace elements on the hydrolysis and acidification phases during the methanization of a maize silage-based feedstock. J. Environ. Chem. Eng. 5, 341-351. https://doi.org/10.1016/j.jece.2016.11.032

Ezebuiro, N. C., Techamanoon, K. and Koerner, I. (2018). Synergistic and antagonistic influences of trace elements on volatile fatty acids degradation and methane production during the biomethanization of a mixture of volatile fatty acids. J. Environ. Chem. Eng. 6, 1455-1467. https://doi.org/https://doi.org/10.1016/j.jece.2 017.12.017

Facchin, V., Cavinato, C., Pavan, P. and Bolzonella, D. (2013). Batch and continuous mesophilic anaerobic digestion of food waste: Effect of trace elements supplementation. Chem. Eng. Trans. 32, 457-462. https://doi.org/10.3303/CET1332077

Feng, X. M., Karlsson, A., Svensson, B. H. and Bertilsson, S. (2010). Impact of trace element addition on biogas production from food industrial waste - Linking process to microbial communities. FEMS Microbiol. Ecol. 74, 226240. https://doi.org/10.1111/j.15746941.2010.00932.x

Fermoso, F. G., Hullebusch, E., Collins, G., Roussel, J., Mucha, A. P. and Esposito, G. (2019). Trace Elements in Anaerobic Biotechnologies. IWA Publishing Alliance House, London, UK.

Frey, P. A. and Hegeman, A. D. (2007). Enzyme reaction mechanism. Oxford University Press, London.

Glass, J. B. and Orphan, V. J. (2012). Trace metal requirements for microbial enzymes involved in the production and consumption of methane and nitrous oxide. Front. Microbiol. 3, 61. https://doi.org/10.3389/fmicb.2012.00061

Gustavsson, J., Svensson, B. H. and Karlsson, A. (2011). The feasibility of trace element supplementation for stable operation of wheat stillage-fed biogas tank reactors. Water Sci. Technol. 64, 320-325.

https://doi.org/10.2166/wst.2011.633

He, Z., Liu, W., Gao, Q., Tang, C., Wang, L., Guo Z., Zhou, A. and Wang, A. (2018). Potassium ferrate addition as an alternative pre-treatment to enhance short-chain fatty acids production from waste activated sludge. Bioresour. Technol. 247, 174-181.

https://doi.org/10.1016/j.biortech.2017.09.073

Illanes, A. (2008). Enzyme biocatalysis: Principles and application. Springer Science + Business Media B.V.

Ingram-Smith, C., Gorrell, A., Lawrence, S. H., Iyer, P., Smith, K. and Ferry, J. G. (2005). Characterization of the acetate binding pocket in the Methanosarcina thermophila acetate kinase. J. Bacteriol. 187, 2386-2394. https://doi.org/10.1128/JB.187.7.23862394.2005

John, B. (2013). Applications of desirability function for optimizing the performance characteristics of carbonitrided bushes. Int. J. Ind. Eng. Comput. 4, 305-314.

Li, J., Ban, Q., Zhang, L., and Jha, A. K. (2012). Syntrophic propionate degradation in anaerobic digestion: A review. Int. J. Agric. Biol. 14, 843-850.

Lo, H. M., Chiang, C. F., Tsao, H. C., Pai, T. Y., Liu, M. H., Kurniawan, T. A., Chao, K. P., Liou, C. T., Lin, K. C., Chang, C. Y., Wang, S. C., Banks, C. J., Lin, C. Y., Liu, W. F., Chen, P. H., Chen, C. K., Chiu, H. Y., Wu, H. Y., Chao, T. W., Chen, Y. R., Liou, D. W. and Lo, F. C. (2012). Effects of spiked metals on the MSW anaerobic digestion. Waste Manag. Res. 30, 32-48.

https://doi.org/10.1177/0734242X10383079

Lukitawesa, P. R. J., Millati, R., SárváriHorváth, I. and Taherzadeh, M. J. (2020). Factors influencing volatile fatty acids production from food wastes via anaerobic digestion. Bioengineered 11(1), 39-52. doi: 10.1080/21655979.2019.1703544. PMID: 31880192; PMCID: PMC7571609.

Mancini, G., Papirio, S., Riccardelli, G, Lens, P. N. L. and Esposito, G. (2018). Trace elements dosing and alkaline pretreatment in the anaerobic digestion of rice straw. Bioresour. 
Technol. 247, 897-903. DOI: 10.1016/j.biortech.2017.10.001

Meegoda, J., Li, B., Patel, K. and Wang, L. (2018). A Review of the Processes, Parameters, and Optimization of Anaerobic Digestion. Dig. Int. J. Environ. Res. Public Heal. 15, 2224.

Myszograj, S., Stadnik, A. and PłuciennikKoropczuk, E., (2019). The Influence of Trace Elements on Anaerobic Digestion Process. Civ. Environ. Eng. Reports 28, 105-115. https://doi.org/10.2478/ceer-2018-0054

Ortner, M., Rameder, M., Rachbauer, L., Bochmann, G. and Fuchs, W. (2015). Bioavailability of essential trace elements and their impact on anaerobic digestion of slaughterhouse waste. Biochem. Eng. J. 99, 107-113.

https://doi.org/10.1016/j.bej.2015.03.021

Osuna, M. B., Zandvoort, M. H., Iza, J. M., Lettinga, G. and Lens, P. N. L. (2003). Effects of trace element addition on volatile fatty acid conversions in anaerobic granular sludge reactors. Environ. Technol. 24, 573-587. https://doi.org/10.1080/09593330309385592

Pobeheim, H., Munk, B., Johansson, J. and Guebitz, G. M. (2010). Influence of trace elements on methane formation from a synthetic model substrate for maize silage. Bioresour. Technol. 101, 836-839. https://doi.org/10.1016/j.biortech.2009.08.076

Ragsdale, S. W. and Pierce, E. (2008). Acetogenesis and the Wood-Ljungdahl pathway of $\mathrm{CO}_{2}$ fixation. Biochim. Biophys. Acta 1784, 1873-98.

https://doi.org/10.1016/j.bbapap.2008.08.012

SAS Institute Inc. (2012a). JMP 10 Design of Experiments Guide. Cary NC: SAS Institute Inc.

SAS Institute Inc. (2012b). JMP 10 Multivariate methods. Cary NC: SAS Institute Inc.

SAS Institute Inc. (2012c). JMP 10 Fitting Linear Models. Cary NC: SAS Institute Inc.

Sascha M. (2014). Field Manual: Scenario Building. ISBN 978-2-87452-314-4.
Suich, R. and Derringer, G. (1980).

Simultaneous optimization of several response variables. J. Qual. Technol. 12, 214-219.

Varum, C. A. and Melo, C. (2010). Directions in scenario planning literature - A review of the past decades. Futures 42, 355-369. https://doi.org/10.1016/j.futures.2009.11.021

Verein Deutscher Ingenieure (2006). 4630 Fermentation of organic materials, characterisation of the substrate, sampling, collection of material data, fermentation tests. Germany.

Wainaina, S., Lukitawesa, K. A. M. and Taherzadeh, M. J. (2019). Bioengineering of anaerobic digestion for volatile fatty acids, hydrogen or methane production: A critical review. Bioengineered, 10(1), 437-458. Doi: 10.1080/21655979.2019.1673937.

Yazdanpanah, A., Ghasimi, D., Kim, M., Nakhla, G. and Hafez, H. (2018). Impact of trace element supplementation on mesophilic anaerobic digestion of food waste using $\mathrm{Fe}$-rich inoculum. Environ. Sci. Pollut. Res. 25, 29240 29255. https://doi.org/10.1007/s11356-0182832-2.

Zhang, C., Lian, J., Jiang, Z., Guo, J., Guo, Y. and Gou, C. (2016). A study of the kinetics and the effect of trace elements on mixed anaerobic fermentative biogas production by ternary quadratic general rotary unitized design. Biotechnol. Biotechnol. Equip. 30(1), 90 - 99. Doi:

$10.1080 / 13102818.2015 .1083886$

Zhang, Y. and Banks, C. J. (2012). Codigestion of the mechanically recovered organic fraction of municipal solid waste with slaughterhouse wastes. Biochem. Eng. J. 68(15), 129-137. https://doi.org/10.1016/j.bej.2012.07.017

Zhang, Y. Banks, C. J. and Heaven, S. (2012). Anaerobic digestion of two biodegradable municipal waste streams. J. Environ. Manage. 104, 166-174. https://doi.org/10.1016/j.jenvman.2012.03.04 3 


\section{Appendices}

Appendix -Table 1: Implementable experimental runs from the combination of five factors $(k)$ including $\mathrm{Ni}, \mathrm{Co}, \mathrm{Se}, \mathrm{Mo}$ and VFA concentration at three levels ( $\mathrm{n}$ ) of low, medium and high concentrations

\begin{tabular}{|c|c|c|c|c|c|}
\hline Treatment & $\begin{array}{c}\text { VFA } \\
\text { Level } \\
\text { mmol/L }\end{array}$ & $\mathbf{N i}$ & $\mathrm{mg} / \mathrm{L}$ & Se & Mo \\
\hline \multicolumn{6}{|c|}{ Low VFA level } \\
\hline R1 & 28 & 0.07 & 0.03 & 0.98 & 0.04 \\
\hline $\mathbf{R 2}$ & 28 & 0.07 & 1.88 & 0.00 & 1.24 \\
\hline R3 & 28 & 0.07 & 3.73 & 0.00 & 0.64 \\
\hline R4 & 28 & 0.07 & 3.73 & 0.98 & 1.24 \\
\hline R5 & 28 & 1.03 & 3.73 & 0.00 & 1.24 \\
\hline R6 & 28 & 1.99 & 0.03 & 0.00 & 0.04 \\
\hline R7 & 28 & 1.99 & 0.03 & 0.98 & 1.24 \\
\hline $\mathbf{R 8}$ & 28 & 1.99 & 3.73 & 0.98 & 0.04 \\
\hline \multicolumn{6}{|c|}{ Medium VFA level } \\
\hline $\mathbf{R 9}$ & 116 & 0.07 & 1.88 & 0.49 & 0.04 \\
\hline R10 & 116 & 1.03 & 0.03 & 0.49 & 1.24 \\
\hline R11 & 116 & 1.03 & 1.88 & 0.98 & 0.64 \\
\hline R12 & 116 & 1.99 & 3.73 & 0.49 & 0.64 \\
\hline \multicolumn{6}{|c|}{ High VFA level } \\
\hline R13 & 213 & 0.07 & 0.03 & 0.00 & 0.64 \\
\hline R14 & 213 & 0.07 & 0.03 & 0.98 & 1.24 \\
\hline R15 & 213 & 0.07 & 3.73 & 0.00 & 1.24 \\
\hline R16 & 213 & 0.07 & 3.73 & 0.98 & 0.04 \\
\hline R17 & 213 & 1.03 & 1.88 & 0.49 & 0.64 \\
\hline R18 & 213 & 1.03 & 3.73 & 0.00 & 0.04 \\
\hline R19 & 213 & 1.99 & 0.03 & 0.98 & 0.04 \\
\hline R20 & 213 & 1.99 & 1.88 & 0.00 & 1.24 \\
\hline R21 & 213 & 1.99 & 3.73 & 0.98 & 1.24 \\
\hline \multicolumn{6}{|l|}{ Control } \\
\hline R28* & 28 & 0.07 & 0.03 & 0.00 & 0.04 \\
\hline R29* & 11 & 0.07 & 0.03 & 0.00 & 0.04 \\
\hline R30* & 213 & 0.07 & 0.03 & 0.00 & 0.04 \\
\hline
\end{tabular}

I. The volatile fatty acid (VFA) mixture contained the following sodium salts in (mg/L) - Acetate: $\leq$ 600 , low; $\geq 2,250$, medium; $\geq 4,500$, high; Butyrate: $\leq 250$, low; $\geq 1,000$, medium; $\geq 2,000$, high; Propionate: $\leq 1000$ low; $\geq 4,000$, medium; $\geq 8,000$, high.

II. Ni, Nickel; Co, Cobalt; Se, Selenium; Mo, Molybdenum;

III. *Control reactors: no TEs supplementation. Values of TEs are concentrations from inoculum;

IV. Units: VFA (mmol/L); Ni, Co, Se and Mo (mg/L) 
Appendix -Table 2: Influences of the TEs supplementation scenarios on biomethanization processes and desirability during mesophilic operation at $37^{\circ} \mathrm{C}$.

\begin{tabular}{|c|c|c|c|c|c|c|c|c|c|}
\hline \multirow[t]{2}{*}{ SCENARIOS } & \multirow{2}{*}{$\begin{array}{c}\text { VFA } \\
(\mathrm{MMOL} / \mathrm{L})\end{array}$} & NI & $\mathrm{CO}$ & SE & MO & \multirow[t]{2}{*}{$\mathbf{A}$} & \multirow[t]{2}{*}{ B } & \multirow[t]{2}{*}{ C } & \multirow[t]{2}{*}{ D } \\
\hline & & \multicolumn{4}{|c|}{$\mathrm{mg} / \mathrm{L}$} & & & & \\
\hline \multirow[t]{6}{*}{ CONTROL } & 10 & 0.07 & 0.03 & 0 & 0.04 & 1.44 & 0.94 & 1.09 & 0.39 \\
\hline & 50 & 0.07 & 0.03 & 0 & 0.04 & 1.15 & 0.98 & 1.13 & 0.35 \\
\hline & 100 & 0.07 & 0.03 & 0 & 0.04 & 0.94 & 1.02 & 1.14 & 0.29 \\
\hline & 150 & 0.07 & 0.03 & 0 & 0.04 & 0.89 & 1.06 & 1.09 & 0.26 \\
\hline & 200 & 0.07 & 0.03 & 0 & 0.04 & 0.99 & 1.09 & 0.98 & 0.28 \\
\hline & 250 & 0.07 & 0.03 & 0 & 0.04 & 1.25 & 1.12 & 0.81 & 0.29 \\
\hline \multirow[t]{6}{*}{ COMPROMISE } & 10 & 0.77 & 1.78 & 0.45 & 0.58 & 1.89 & 1.43 & 1.64 & 0.76 \\
\hline & 50 & 0.77 & 1.78 & 0.45 & 0.58 & 1.63 & 1.39 & 1.65 & 0.68 \\
\hline & 100 & 0.77 & 1.78 & 0.45 & 0.58 & 1.44 & 1.33 & 1.6 & 0.61 \\
\hline & 150 & 0.77 & 1.78 & 0.45 & 0.58 & 1.42 & 1.27 & 1.51 & 0.56 \\
\hline & 200 & 0.77 & 1.78 & 0.45 & 0.58 & 1.55 & 1.2 & 1.35 & 0.54 \\
\hline & 250 & 0.77 & 1.78 & 0.45 & 0.58 & 1.84 & 1.13 & 1.14 & 0.52 \\
\hline \multirow[t]{6}{*}{ VFA-120 } & 10 & 1.94 & 3.74 & 0.1 & 1.61 & 2.2 & 1.5 & 1.99 & 0.83 \\
\hline & 50 & 1.94 & 3.74 & 0.1 & 1.61 & 1.89 & 1.48 & 1.93 & 0.79 \\
\hline & 100 & 1.94 & 3.74 & 0.1 & 1.61 & 1.65 & 1.45 & 1.8 & 0.72 \\
\hline & 150 & 1.94 & 3.74 & 0.1 & 1.61 & 1.56 & 1.41 & 1.61 & 0.66 \\
\hline & 200 & 1.94 & 3.74 & 0.1 & 1.61 & 1.63 & 1.36 & 1.37 & 0.61 \\
\hline & 250 & 1.94 & 3.74 & 0.1 & 1.61 & 1.87 & 1.31 & 1.07 & 0.54 \\
\hline \multirow{6}{*}{$\begin{array}{c}\text { VFA- } \\
\text { DEPENDENT }\end{array}$} & 10 & 1.88 & 4.21 & 0.32 & 1.61 & 1.96 & 1.81 & 1.82 & 0.89 \\
\hline & 50 & 1.92 & 4.01 & 0.19 & 1.61 & 1.91 & 1.58 & 1.72 & 0.82 \\
\hline & 100 & 1.94 & 3.74 & 0.1 & 1.61 & 1.62 & 1.54 & 1.7 & 0.73 \\
\hline & 150 & 2.15 & 3.75 & 0 & 1.61 & 1.58 & 1.38 & 1.63 & 0.66 \\
\hline & 200 & 2.04 & 3.62 & 0.03 & 1.61 & 1.6 & 1.42 & 1.41 & 0.62 \\
\hline & 250 & 0.8 & 2.2 & 0.53 & 0 & 1.85 & 1.31 & 1.22 & 0.59 \\
\hline
\end{tabular}

A-relative $\mathrm{Y}_{\mathrm{VFA}-\mathrm{DR}}$ or relative VFA degradation rate; B-relative $\mathrm{Y}_{\mathrm{VFA}-\mathrm{RT}}$ or relative VFA retention time; Crelative $\mathrm{Y}_{\mathrm{CH} 4}$ production; and $\mathbf{D}$-desirability 